\title{
Journal of Ornithology \\ Postcopulatory sexual selection favors fertilization success of restocking hybrid quails over native Common quails (Coturnix coturnix) \\ --Manuscript Draft--
}

\begin{tabular}{|c|c|}
\hline Manuscript Number: & JORN-D-15-00067R1 \\
\hline Full Title: & $\begin{array}{l}\text { Postcopulatory sexual selection favors fertilization success of restocking hybrid quails } \\
\text { over native Common quails (Coturnix coturnix) }\end{array}$ \\
\hline Article Type: & Original Article \\
\hline Keywords: & $\begin{array}{l}\text { Coturnix, criptic female choice, introgression, postcopulatory selection, quail, } \\
\text { restocking, sperm competition. }\end{array}$ \\
\hline Corresponding Author: & $\begin{array}{l}\text { Ines Sanchez-Donoso, Dr. } \\
\text { SPAIN }\end{array}$ \\
\hline \multicolumn{2}{|c|}{$\begin{array}{l}\text { Corresponding Author Secondary } \\
\text { Information: }\end{array}$} \\
\hline \multicolumn{2}{|c|}{ Corresponding Author's Institution: } \\
\hline \multicolumn{2}{|c|}{$\begin{array}{l}\text { Corresponding Author's Secondary } \\
\text { Institution: }\end{array}$} \\
\hline First Author: & Ines Sanchez-Donoso, Dr. \\
\hline \multicolumn{2}{|c|}{ First Author Secondary Information: } \\
\hline \multirow[t]{6}{*}{ Order of Authors: } & Ines Sanchez-Donoso, Dr. \\
\hline & Pablo Antonio Morales-Rodriguez \\
\hline & Manel Puigcerver, Dr. \\
\hline & José Ramón Caballero de la Calle \\
\hline & Carles Vilà, Dr. \\
\hline & José Domingo Rodríguez-Teijeiro, Dr. \\
\hline \multicolumn{2}{|c|}{ Order of Authors Secondary Information: } \\
\hline \multicolumn{2}{|l|}{ Funding Information: } \\
\hline Abstract: & $\begin{array}{l}\text { Postcopulatory sexual selection plays an important role in the reproductive success of } \\
\text { males in many species. Differences in fertilization success could affect rates of } \\
\text { admixture and genetic introgression between divergent lineages. We investigated } \\
\text { sperm precedence in matings in captivity involving Common quails (Coturnix coturnix) } \\
\text { and farm quails of hybrid origin (C. coturnix x domestic Japanese quail, C. japonica), } \\
\text { the last used in restocking practices to increase hunting bags. These interspecific } \\
\text { matings in natural conditions are claimed to represent an important threat for the } \\
\text { conservation of native Common quail populations. Results showed that fertilization } \\
\text { success of each male depended on 1) the time it spent with the female, 2) the } \\
\text { presence of sperm from a previous male in the female oviduct, 3) the time that the } \\
\text { previous partner had been copulating with the female, and, most importantly, 4) the } \\
\text { genetic origin of the male (wild or farm). Farm hybrid males showed higher fertilization } \\
\text { success than wild Common males, they needed less time with the female to fertilize } \\
\text { the same proportion of eggs. The presence of sperm from another male in the female } \\
\text { oviduct reduced the percentage of fertilized eggs by a male. However, this reduction } \\
\text { was higher for wild males when the precedent mate was a farm male. In summary, the } \\
\text { sperm of farm hybrid males may outcompete the sperm of native males and this could } \\
\text { be favoring the introgression of domestic Japanese alleles into the Common quail } \\
\text { population, thus constituting a severe conservation threat to wild Common quail } \\
\text { populations. }\end{array}$ \\
\hline
\end{tabular}


1 Postcopulatory sexual selection favors fertilization success of restocking hybrid 2 quails over native Common quails (Coturnix coturnix)

4 Ines Sanchez-Donoso ${ }^{1,2}{ }^{*}$, Pablo Antonio Morales-Rodriguez ${ }^{3,4}$, Manel Puigcerver ${ }^{5}$, José 5 Ramón Caballero de la Calle ${ }^{3}$, Carles Vilà ${ }^{1}$, José Domingo Rodríguez-Teijeiro ${ }^{2}$.

6

71 Conservation and Evolutionary Genetics Group, Integrative Ecology Department, Estación 8 Biológica de Doñana - Consejo Superior de Investigaciones Científicas (EBD-CSIC), Seville, 9 Spain.

102 Animal Biology Department, University of Barcelona, Barcelona, Spain.

113 Agroforestry and Genetics Science and Technology Department, University of Castilla - La 12 Mancha (UCLM), Ciudad Real, Spain.

134 Vegetal Production and Agrarian Technology Department, University of Castilla - La Mancha 14 (UCLM), Ciudad Real, Spain.

155 Experimental Sciences and Mathematics Didactics Department, University of Barcelona, 16 Barcelona, Spain.

*Corresponding author: Ines Sanchez-Donoso, ines.sanchezdonoso@gmail.com 


\section{ABSTRACT}

Postcopulatory sexual selection plays an important role in the reproductive success of males in many species. Differences in fertilization success could affect rates of admixture and genetic introgression between divergent lineages. We investigated sperm precedence in matings in captivity involving Common quails (Coturnix coturnix) and farm quails of hybrid origin (C. coturnix $\mathrm{x}$ domestic Japanese quail, C. japonica), the last used in restocking practices to increase hunting bags. These interspecific matings in natural conditions are claimed to represent an important threat for the conservation of native Common quail populations. Results showed that fertilization success of each male depended on 1) the time it spent with the female, 2) the presence of sperm from a previous male in the female oviduct, 3) the time that the previous partner had been copulating with the female, and, most importantly, 4) the genetic origin of the male (wild or farm). Farm hybrid males showed higher fertilization success than wild Common males, they needed less time with the female to fertilize the same proportion of eggs. The presence of sperm from another male in the female oviduct reduced the percentage of fertilized eggs by a male. However, this reduction was higher for wild males when the precedent mate was a farm male. In summary, the sperm of farm hybrid males may outcompete the sperm of native males and this could be favoring the introgression of domestic Japanese alleles into the Common quail population, thus constituting a severe conservation threat to wild Common quail populations.

Keywords: Coturnix, criptic female choice, introgression, postcopulatory selection, quail, restocking, sperm competition.

\section{INTRODUCTION}

Female promiscuity is widespread in nature (Birkhead and Møller 1998), creating a favorable scenario for sexual selection both before and after copulation (Shuster et al. 2013). Postcopulatory sexual selection plays an important role in sexual evolution (e.g. Birkhead and Møller 1998; Birkhead and Pizzari 2002; Birkhead et al. 2009) and can occur through different mechanisms. One of them is sperm competition, where gametes of different males compete to fertilize the same set of ova (Parker 1970; Pizzari and Parker 2009). Another mechanism is cryptic female choice, by which females are able to bias paternity in favor of a particular male after having copulated with several males (Eberhard 1996; Kempenaers 1999; Pitnick and 
Brown 2000; Birkhead and Pizzari 2002; Dean et al. 2011). Both mechanisms are usually closelly related and, thus, difficult to disentangle (Birkhead 1998), resulting in sperm precedence patterns by which some gametes take precedence over others when fertilizing ova.

Sperm competition and cryptic female choice are facilitated by the capability of females to store viable sperm in their reproductive tract. Sperm storage permits that sperm from several males compete to fertilize the ovum and allows females to impose some kind of postcopulatory selection, playing an important role in mating strategies (Smith 1984; Birkhead and Parker 1997). Sperm-Storage Tubules (SST) are the structures for sperm storage found in the oviduct of birds and some other taxa (Birkhead and Møller 1993; Pearse and Avise 2001). The persistence of viable sperm within the female varies among bird species, from days to weeks (Birkhead and Møller 1992a), allowing the fertilization of ova long after copulation (Cohen 1977; Shugart 1988; Birkhead and Møller 1993).

The Common quail (Coturnix coturnix) is a migratory galliform species that inhabits grasslands and croplands in Europe, North Africa and West Asia during the breeding season and African grasslands during winter (Guyomarc'h et al. 1998; Rodríguez-Teijeiro et al. 2012). It is a game species, with economic importance in several European countries, where thousands of birds are hunted every year (Guyomarc'h 2003). Although the census size is estimated to be globally large, their populations are annually reinforced in many hunting grounds with the release of thousands of quails bred in farms to boost the hunting population. The number of individuals released can be up to 5 to 20 times larger than the breeding population in the same areas (Sanchez-Donoso et al. 2012). A recent genetic analysis has shown that farm individuals are not Common quails but descendants of crosses with domestic Japanese quail (C. japonica, Sanchez-Donoso et al. 2012). Released farm quails are competing with native quails for mating opportunities and their admixture in the wild has been identified as the main conservation problem for Common quail populations (Guyomarc'h 2003; Perennou 2009). Domestic Japanese quails have been artificially selected to show, among other traits, a reduced migratory drive. It has been shown that this character can be inherited by hybrids (Derégnaucourt 2000 in Barilani et al. 2005; Derégnaucourt et al. 2005a, b), as farm quails intended for restocking, so it could impact natural populations if they interbreed. This admixture could entail a loss of migratory impulse and a sedentariness of native populations, which would thus winter in unfavourable latitudes. Moreover, growing in captivity makes farm quails poorly fitted to the wild conditions when released. These individuals suffer a higher predation (Puigcerver et al. 2014) and could also be subject to farm diseases or parasites due to lower immune system response as a result of relaxed selection in captivity (as in other related species, Villanúa et al. 2008). Recent studies have confirmed that farm and wild quails interbreed and produced offspring in the wild (Puigcerver et al. 2014; Sanchez-Donoso et al. 2014).

One of the factors that could determine the success of the admixture between wild and farm quails is postcopulatory sexual selection. Since domestic Japanese quails may have been 
artificially selected to be highly fertile (Pérez y Pérez 1966), their male farm descendants could be outcompeting wild males, which would be promoting the introgression of invasive alleles. Several characteristics of both Common and domestic Japanese quails lead to think that they can be exposed to postcopulatory sexual selection (either by sperm competition and/or by cryptic female choice), which could be influencing the success of hybridization in the wild.

(i) Females are polyandrous in both species. Domestic Japanese quail females are receptive to multiple males in laboratory settings and males can force copulations if females are not receptive (Adkins-Regan 1995). Common quail females usually mate with several males in a single reproductive attempt (Rodríguez-Teijeiro et al. 2003). Although male and female create a bond that lasts several days while the female is sexually active, opportunistic extra-pair copulations or mate-switching often occur during that time (Rodrigo-Rueda et al. 1997).

(ii) Females of both species present SST which would allow ejaculates from different males to accumulate, even if matings occur on different days. Domestic Japanese quail females can store viable sperm for a median of 8 days (Sittmann and Abplanalp 1965; Birkhead and Fletcher 1994).

(iii) Males of both species have large testes relative to their body mass (Puigcerver 1990; Rodríguez-Teijeiro et al. 1992) which is a common feature in bird species with high frequency of extrapair paternity (Møller 1991; Møller and Briskie 1995) and in species with intense sperm competition (Møller 1988; Jennions and Passmore 1993; Gage 1994), because the investment in sperm production is increased (Clulow and Jones 1982; Møller 1989; Cook 1997).

(iv) Quail males have a penis (Puigcerver et al. 1994), which could facilitate forced copulations (as in waterfowl, Coker et al. 2002) and some degree of postcopulatory female selection could have developed to manage the output of these copulations (Briskie and Montgomerie 1997).

In this paper we investigated whether postcopulatory sexual selection exists between the sperm of Common quail males and hybrid males intended for restocking. We assessed if fertilization success for both kinds of males was the same and also how fertilization success was modified when other sperm was found in the female's oviduct. To study these questions, we carried out an experiment in captivity with females mating with wild Common males or with hybrid farm males. Some of those females were secondarily exposed to another male of the same or different genetic origin. We studied the sperm precedence pattern from these crosses by genetically analyzing the resulting embryos and, thus, we assessed the fertilization success for each kind of male. All in all, we investigated whether postcopulatory sexual selection between farm-reared hybrids and Common quails could contribute to the admixture between these two lineages in the wild, increasing the threat imposed by the massive restocking campaigns. 


\section{METHODS}

\section{Experimental design}

132 Experimental crosses were initially attempted using wild Common females captured from the 133 field. However, they did not succeeded in breeding in captive conditions, since it is very difficult 134 for pure Common quail females to lay eggs in captivity (Caballero de la Calle and Peña Montañés 1997). Therefore, experiments were conducted with 16 females from an experimental farm of the University of Castilla-La Mancha (Spain), which were descendants of admixed females backcrossed with wild Common quail males for about 20 generations, so they had domestic Japanese mitochondrial DNA (Barilani et al. 2005) but nuclear DNA indistinguishable from Common quail (Sanchez-Donoso et al. 2012).

Twenty-seven males were used in the experimental crosses. Ten of them were pure Common quails (without any evidence of admixed ancestry) captured from the wild in three cereal crop areas in Spain (four in Barcelona, four in Ciudad Real and two in Seville provinces; see Puigcerver et al. 2007 for capture methods); the remaining 17 males were hybrid individuals with variable degree of admixture, hatched and reared in three different Spanish game farms intended for restocking. Species identification for all individuals was done following SanchezDonoso et al. (2012) (data not shown). All individuals were about one year old to avoid any possible effect of age on their fertility (Santos et al. 2013).

Quails were kept in aviaries during at least eight months before the start of the experiments, in order to get them habituated to captive conditions. They were moved to individual $20 \times 20 \times 20 \mathrm{~cm}$ cages fourteen days before the beginning of the experiments to ensure that no viable sperm was stored in females' SST (Birkhead and Fletcher 1994; Miranda et al. 2013) and to avoid sperm depletion in males (Preston et al. 2001). All experimental crosses were done during the natural breeding season of the Common quail (from the beginning of June to the end of July of 2010).

Females remained in their cage during the experiments to avoid disturbances and males were the ones moved in and out the cages as needed (see below). Individuals were used just once in the experiment to avoid any effect of their copulatory history over subsequent pre- and postcopulatory traits or behavior. All individuals were sexually active during the experiments.

159 Female sexual maturity was confirmed by their capability of laying eggs while for male its sexual activity status was assessed by their swollen cloaca (measured in length; Sachs 1969; Siopes and Wilson 1975) and/or the presence of foam in the cloacal gland (Adkins-Regan 1995). Physical condition and health were assessed by the weight and physical appearance and only individuals in good condition were used in the experiments. 

Models (GLMs) were fitted using the $\mathrm{glm}()$ function and constructed assuming a Binomial error distribution and a Logit link function. GLMs were tested for the presence of outliers, homoscedasticity, normality and overdispersion. Overdispersed models were recalculated assuming a Quasibinomial error distribution. The significance of the variables studied was evaluated by an analysis of deviance with the function Anova () available in the package car (Fox and Weisberg 2011). In models that were not overdispersed, the analysis of deviance was evaluated by a likelihood-ratio test (Chi-square test); an F-test was used in overdispersed models.

\section{Experiment 1: Simple crosses - Male fertilization potential}

A set of simple crosses (one male and one female) was designed to study the fertility of farm and wild Common quail males without other sperm in the female's oviducts. Six wild Common males and 10 farm males were caged with a female each. After the female laid an average of six eggs (from 3 to 8 ), the male was removed from the cage and Experiment 1 finished. The number of days that female and male were caged together was registered, as well as daily laying events (absence/presence of egg laid). Eggs were collected every day, individually labeled and incubated in the laboratory during a week. After that time, they were opened to determine whether they were fertilized or not by the presence or absence of an embryo.

We analyzed with a GLM whether genetic origin of males could affect their egg fertilization capability. The proportion of fertilized eggs during the time male and female were caged together was the response variable and male origin was the explanatory factor tested. The number of days the male spent with the female was added as a covariate, since we suspected that it could have some effect on the proportion of fertilized eggs.

\section{Experiment 2: Double crosses - Sperm competition}

To study the possible sperm competition between males of the same or different origin, we carried out a second experiment with 11 females after concluding Experiment 1 (four females that had been with wild males and seven with farm males). At the same time that the first male (M1) was taken out of the cage, it was replaced by a second male (M2). M2 was caged with the female until she laid an average of 7 (from 3 to 11) more eggs. After that, M2 was removed from the cage, and Experiment 2 finished. Three different types of crosses were done regarding the origin of the males and the order in which they encountered the female: 1) wild M1 - farm M2 (w-f); 2) farm M1 - wild M2 (f-w); 3) farm M1 - farm M2 (f-f). Four crosses were performed for the 
Eggs were handled as in Experiment 1. Number of eggs laid and eggs fertilized were registered. We genotyped the embryos and assessed their paternity. Since sperm stored in the female oviduct can fertilize ova with the same probability during six days after mating (Birkhead and Fletcher 1994), we registered the number of eggs fertilized by each male and the number of non-fertilized eggs laid during the first six days after the male exchange. During that period, fertilization by M1 or M2 would only depend on the possible postcopulatory selection over the sperm of the two males.

Firstly, we analyzed whether the presence of sperm from a previous male, stored in the female's oviduct, had an effect on the proportion of eggs fertilized by a second male. The proportion of eggs sired by a male over the total number of eggs laid was the response variable of the GLM. Presence or absence of sperm from a previous male was the factor of interest. Wild and farm males were analyzed independently to observe the stored sperm effect over each kind of male. Secondly, we tested whether the proportion of non fertilized eggs changed before and after male exchange, to assess if it was dependent on the presence of sperm of one or two males in the oviduct. Finally, we studied whether fertilization capability of M2 was determined by its own origin and the origin of the previous male. We tested differences in the proportion of embryos sired by M2 among the three male arrangements: $w-f, f-w$ and $f-f$. The number of days M1 had been with the female was included as a covariate.

\section{Experiment 3: Time alone - Sperm longevity in SST}

After removing M2, the female was left in the cage during 14 days. Eggs laid were collected, incubated and checked for embryos as before, and paternity analyses were done for all embryos. We registered the number of eggs and length of time during which these were fertilized in the absence of males.

\section{Paternity analyses}

225 Paternity of embryos was assessed by genetic analyses using a panel of autosomal microsatellite loci. A blood sample $(100 \mu \mathrm{l})$ was obtained for each adult and a tissue sample for each embryo. Samples were stored at $-20^{\circ} \mathrm{C}$ in $95 \%$ ethanol until DNA was extracted using DNeasy Blood \& Tissue Kit (Qiagen), following manufacturer's protocols. Individuals were genotyped for 11 unlinked autosomal microsatellite loci originally developed for Japanese quail by Kayang et al. (2002; 2004). These markers were highly polymorphic and had previously been used for hybrid identification (Sanchez-Donoso et al. 2012; Sanchez-Donoso et al. 2014). Some loci were amplified by polymerase chain reaction (PCR) in a multiplex (some of them with primers modified to facilitate multiplexing, as in Sanchez-Donoso et al. 2014), while others were amplified separately and subsequently pooled before electrophoresis (detailed protocols are 
available upon request). All PCR products were electrophoresed on an $A B I 3730$ sequencer (Applied Biosystems), following manufacturer's protocols. Alleles were sized and scored using the software GeneMapper v3.5 (Applied Biosystems).

Paternity of embryos was assigned by using the maximum likelihood method implemented in CERVUS 3.0.3 (Kalinowski et al. 2007). This software assigns parentage based on a pair-wise likelihood comparison. Simulations, based on allele frequency analyses, were run in advance to estimate the significance of these differences between likelihoods for a defined confidence level (see Marshall et al. 1998; Kalinowski et al. 2007; for details). Each mating experiment was analyzed separately. Simulations of parentage were run for 100,000 offspring. For all embryos analyzed, paternity was unambiguously assigned to one of the putative parents with a probability over $99 \%$. In all cases, genetic analyses confirmed as mother the female in the cage, showing the reliability of the markers used in the study.

\section{RESULTS}

Fertile eggs did not necessarily occur on successive days, but could be separated by days with non-fertilized eggs or without egg. This laying pattern was concordant with previous findings (Adkins-Regan 1995). In all cases, no more than one egg was laid per day.

\section{Experiment 1: Simple crosses - Male fertilization potential}

The duration of the experiment was variable among cases, lasting on average 18.6 days (standard deviation, $S D=12.1)$. During this time, females laid 6.0 eggs on average $(S D=1.2)$.

Both male origin and number of days the male spent with the female had a significant effect on the proportion of eggs fertilized. The longer the male spent caged with the female, the larger the proportion of fertilized eggs $\left(\chi^{2}{ }_{1}=5.93, p=0.015\right.$, Fig. 1). Although this pattern was observed for both types of males, there were clear differences between them $\left(\chi_{1}^{2}=7.19\right.$, $p=0.007$ ): for the same amount of time, farm males fertilized more eggs than wild males (Fig. 1).

\section{Experiment 2: Double crosses - Sperm competition}

Experiment 2 lasted 10.4 days on average $(S D=2.5)$ during which each of the 11 females laid 7.0 eggs on average $(S D=2.8)$. 
The first egg sired by M2 was one of the first three eggs laid during this experiment and during the four first days after changing males. After that, a switch in paternity occurred in the egg series and none of the following eggs was sired by M1. In eight cases, eggs were fertilized by sperm from M1 stored in the female's oviduct after the change in males had taken place. In two of these eight cases, M1 sired only the first egg after the change of males, in four M1 sired the two first eggs, and in two M1 was the father of the three first eggs.

The presence of sperm from a previous male stored in the female's oviduct led to a reduction in the proportion of eggs fertilized by a male (Fig. 2). For wild males, the reduction was $74 \%$ (proportion of eggs fertilized by a wild male as M1 vs. proportion of eggs fertilized as $M 2$-with a farm male as $M 1-: F_{(1,8)}=12.88, p=0.007$, Fig. 2). For farm males, the reduction was $31 \%$, less accentuated but still significant (farm male as $M 1$ vs. farm male as $M 2: F_{(1,15)}=5.01$, $\mathrm{p}=0.041$, Fig. 2). In this case, the origin (wild or farm) of the previous male (M1) did not have a significant effect $\left(F_{(1,5)}=0.01, p=0.923\right)$.

The proportion of non-fertilized eggs did not differ significantly before and after the male exchange $\left(F_{(1,25)}=0.26, p=0.617\right)$. This indicated that the reduction in the proportion of fertilized eggs by a male when another male (M1) had been with the female before was due to the presence of the eggs fertilized by $\mathrm{M} 1$, and not due to non fertilized eggs after the male exchange.

The proportion of embryos sired by M2 (thus, excluding non-fertilized eggs) was dependent on the combination of males with regard to their origin while controlling for the time $\mathrm{M} 1$ had been before with the female $\left(\chi_{2}^{2}=10.66, p=0.005\right)$. The longer the stay of M1 with the female, the lower proportion of eggs fertilized by M2 (Fig. 3). Farm males that copulated after another male (independently of its origin) fertilized a higher proportion of eggs than wild males that copulated after a farm male $\left(\chi^{2}{ }_{1}=10.54, p=0.001\right)$. Even though the proportion of eggs fertilized by M2 males was reduced, the proportion of eggs fertilized by farm males as M2 was not significantly different from $M 1$ wild males $\left(F_{(1,11)}=0.25, p=0.625\right)$.

\section{Experiment 3: Time alone - Sperm longevity in SST}

Out of the 11 females in Experiment 2, one did not lay eggs during the time she was left alone, so it was not taken into account for Experiment 3. The ten remaining females were monitored in Experiment 3. Among them, three laid exclusivelly non fertilized eggs while six laid fertilized and non fertilized eggs. These females retained viable sperm during a maximum of 10 days (average: 6.2 ; $S D=2.5$ ). During this time, a maximum of 7 eggs could be fertilized by the sperm stored in the SST (average: 3.5; SD=2.2). Eggs were sired in all cases by the last male that stayed with the female. 


\section{DISCUSSION}

306

307

308

309

310

311

Several factors can modulate a male's ejaculate competitiveness (Cook et al. 1997; Pitnick et al. 2009; Pizzari and Parker 2009), such as ejaculate size (volume and absolute number of spermatozoa; Martin et al. 1974; Gage and Morrow 2003), spermatozoan traits (length, swimming speed or longevity), seminal plasma biochemistry, and the interactions between the ejaculates of competing males and also with the female's oviduct (Cook et al. 1997; Pitnick et al. 2009; Pizzari and Parker 2009). In the case of the quail, also the production of foam by the proctodeal gland has been found to be of importance in male fertility (Cheng et al. 1989; AdkinsRegan 1999; Finseth et al. 2013). All these traits, together with cryptic female choice, can contribute to determine the relative fertilization success of the different males mating with the same female. However, in this paper we have not focused on the mechanisms underlying the sperm precedence pattern, but on the output of this process.

Results showed that the time a male spent caged with a female had a positive effect on his probability of fertilising a female's egg. The longer the male stayed with the female, the higher the proportion of eggs from the clutch fertilized by his sperm. This period also had an effect on the fertilization success for any male subsequently copulating with that same female. This time dependency of the fertilization success would explain the natural mating behavior of the Common quail. Male and female establish a pair-bond for a period of time during which the male guards his partner against possible extra-pair copulations (EPC). Since mate-switching has also been observed (Rodrigo-Rueda et al. 1997), the longer a male guards its mate, the higher the chances will be to fertilize the clutch even if the female copulates later with another male. In addition, our results also show that quail sperm could be viably maintained in the female's oviduct during an average of 6 days, with an average of 3.5 eggs fertilized during those days (what is not very different from previous findings, Birkhead and Fletcher 1994). Taking into account that Common quail clutches usually total about 10 eggs (Gallego et al. 1993), males would be unlikely to fertilize entire clutches by mating just once or a few times over a short time period with the same female, so the guarding behavior is likely to increase their siring potential.

Previous studies have already reported that males that copulate more times or for longer have higher fertilization success (Dickinson 1986; Parker and Simmons 1991). A higher number of copulation events increases the volume of sperm introduced into the female, what increases the siring probability of that male. A male's fertilization success will generally increase with the quantity of his sperm relative to that of other males (Parker et al. 1990). In our study, after the first egg sired by the second male (M2) was laid, a change in the paternity in the egg series occurred, and none of the following eggs was sired by the first male (M1), neither while being with M2 nor when she was alone. Our results did not support the last-male precedence pattern observed in other bird species (Warren and Kilpatrick 1929; Cheng et al. 1983; Briskie 1996; 
Birkhead and Pizzari 2002) - by which the last male that copulates with the female is the one siring the majority of the clutch -, since in our case not only the order of the males would have been affecting the sperm precedence pattern, but this pattern would be under the effect of the time male and female would had been copulating. On the contrary, our results did not completely reject the "last in, first out" pattern (Birkhead and Møller 1992b; Stai and Searcy 2010), by which some kind of sperm stratification occurs in the SST: the sperm of the first male is stored at the bottom of the tubules and the sperm of subsequent mates is deposited in top of it, this sperm being those that would fertilize eggs first. When this has been used up, the sperm beneath it gets exposed, so the last eggs are fertilized by the first male sperm. We did observe a complete replacement of the male siring the embryos after a given point. However, since in our case embryo paternity was determined by the order of males and the length of time spent with the female, we do not know if a shorter stay of M2 would allow the reappearance of eggs sired by M1. In any case, some eggs were fertilized by M1 after M2 had been introduced in the cage, which implies that it is not just the last sperm inseminated that will fertilize eggs. When a male stops copulating with a female, the amount of sperm in the female's oviduct gets reduced through time (Birkhead and Fletcher 1994) because it is used up fertilizing ova and because there is a passive sperm loss that makes its viability decline (Birkhead et al.1995; Birkhead and Pizzari 2002). The reduction of viable sperm stored also reduces the probability of fertilization. Our results supported this observation, since fertilization of eggs stopped after some time being without a male. When a second male inseminated sperm into the female's oviduct, the first male's fertilization success would be reduced faster, by passive sperm loss plus by competition with an increasing quantity of sperm from the second male.

Results from this study show that farm males had higher fertilization success than wild males. Farm males needed to spend less time paired with the female than Common males to sire the same proportion of embryos in a clutch. This implies that farm males during the breeding season are potentially able to fertilize a larger number of eggs, even in just a few days, thus gaining a competitive advantage.

Previous matings by the female reduced male's fertilization success. This reduction in the proportion of eggs fertilized by the second partner was because some of them were sired by the previous mate, since the overall fertilization success was not affected by the presence of sperm from more than one male. This reduction depended again on the amount of time the previous partner was with the female: it was less accentuated when the time available for copulation with the first male had been shorter. However, this reduction in the fertilization success was also affected by the origin of the second male: farm males suffered a less accentuated reduction than wild males. In fact, the proportion of eggs that farm males could fertilize in the presence of competitor's sperm in the female's oviduct was not different from the proportion of fertilized eggs by Common quail males when no other sperm was present. This could also give farm males a great advantage to fertilize eggs over Common quail males. 
Differences in sperm competitiveness have been observed between poultry breeds (Prieto et al. 2011; Santiago-Moreno et al. 2014), that implies that a heritable component may be playing a role. The domestication process and selection for increased productivity in captivity could have increased fertility in many domestic species (Darwin 1868). This could also be the case for domestic Japanese quails that contributed to the origin of the farm quails analyzed here. The results of this study suggest that restocked farm quails may have higher fertility than wild Common quails and may dominate sperm competition. Similar results could have been obtained if the wild birds used in the mating experiments performed worse due to the lack of habituation to life in captivity. However, we tried to prevent this possibility by keeping in captivity all the birds used in these experiments for at least eight months before the beginning of the study. The higher fertility potential of domestic Japanese males over Common quail males would also be supported by their relative testes size: domestic Japanese males show a higher gonadal index (weight of both testes x 100) / body weight) (2.26 g, Clulow and Jones 1982) than Common quail males (1.75 g, Puigcerver 1990). Since relative testes size has been described as a good indicator of sperm competitiveness potential (Møller 1988; Jennions and Passmore 1993; Gage 1994), it would be explaining the observed pattern of fertilization success in favor of domestic Japanese males.

Our results indicate that restocking practices have the potential for a higher impact on the native population than initially suspected by just considering the number of crosses between wild and farm quails. Puigcerver et al. (2014) have shown that, despite a higher mortality for restocked quails and the preference for intra-specific matings, interspecific matings in natural conditions can occur. In fact, Sanchez-Donoso et al. (2014) have detected introgression of alleles of farm origin into wild Common quail populations. In the present study, we have detected an advantageous postcopulatory selection in favor of males of farm origin. These results indicate that a relatively small number of successful interspecific matings could have an important contribution to the introgression of farm alleles into Common quail populations. Given the superior reproductive potential of the quails of farm origin, we advice against restocking practices.

\section{ACKNOWLEDGMENTS}

The authors are most grateful to María Isabel Calle for technical assistance in the experiments and Manuela González-Suárez for statistical advice. Logistical support was provided by Serveis 
414 de Galiana" of the University of Castilla - La Mancha. The "Programa para la Captación del

415 Conocimiento para Andalucía" (C2A) from the Andalusian Government and the "Ajuts per a la 416 formació i contractació de personal investigador novell" (FI grant) from the Catalan Government 417 hired Ines Sanchez-Donoso. The Spanish Science Ministry (CGL2007-63199/BOS project), the 418 "Agència de Gestió d'Ajuts Universitaris i de Recerca" from the Catalan Government 419 (2009SGR481 project) and the University of Castilla - La Mancha (PL20112190-UCLM and 420 PL20101695-UCLM projects) gave financial support.

421 All appropriate ethics and other approvals were obtained for this research. The 422 experimental procedure was conducted according to the guidelines of the Federation of 423 European Laboratory Animal Science Associations (FELASA). It fulfilled the ethic 424 recommendations of the European Union and the Spanish legislation and was approved by the 425 Ethics Committee on Animal Experimentation from the University of Castilla-La Mancha (CEEA $\left.426 \mathrm{n}^{0}: 1101.04,1201.10\right)$. 


\section{REFERENCES}

430

Adkins-Regan E (1995) Predictors of fertilization in the Japanese quail, Coturnix japonica. Anim Behav 50:1405-1415.

Adkins-Regan E (1999) Foam produced by male Coturnix quail: what is its function? Auk 116:184-193.

Barilani M, Derégnaucourt S, Gallego S, Galli L, Mucci N, Piombo R, Puigcerver M, Rimondi S, Rodríguez-Teijeiro JD, Spanò S, Randi E (2005) Detecting hybridization in wild (Coturnix c. coturnix) and domesticated (Coturnix c. japonica) quail populations. Biol Cons 126:445455.

Birkhead TR (1998) Cryptic female choice: criteria for establishing female sperm choice. Evolution 52:1212-1218.

Birkhead TR, Fletcher F (1994) Sperm storage and the release of sperm from the sperm storage tubules in Japanese Quail Coturnix japonica. Ibis 136:101-105.

Birkhead TR, Hosken DJ, Pitnick S (2009) Sperm Biology: An Evolutionary Perspective. Elsevier.

Birkhead TR, Møller AP (1992a) Numbers and size of sperm storage tubules and the duration of sperm storage in birds: A comparative study. Biol J Linn Soc 45:363-372.

Birkhead TR, Møller AP (1992b) Sperm competition in birds: evolutionary causes and consequences. Academic Press.

Birkhead TR, Møller AP (1993) Sexual selection and the temporal separation of reproductive events: sperm storage data from reptiles, birds and mammals. Biol J Linnean Soc 50:295311.

Birkhead TR, Møller AP (1998) Sperm competition, sexual selection and different routes to fitness. In: Birkhead TR, Møller AP (eds) Sperm competition and sexual selection. Academic Press, pp 757-781.

Birkhead TR, Parker GA (1997) Sperm competition and mating systems. In: Krebs JR, Davies NB (eds) Behavioural ecology: an evolutionary approach. Blackwell, pp 121-145.

Birkhead TR, Pizzari T (2002) Postcopulatory sexual selection. Nature Rev Genet 3:262-273. 
Birkhead TR, Wishart GJ, Biggins JD (1995) Sperm precedence in the domestic fowl. Proc R Soc Lond [Biol] 261:285-292.

Briskie JV (1996) Spatiotemporal of sperm storage and last-male sperm precedence in birds. Funct Ecol 10:375-383.

Briskie JV, Montgomerie R (1997) Sexual selection and the intromittent organ of birds. J Avian Biol 28:73-86.

Caballero de la Calle JR, Peña Montañés JC (1997) La explotación cinegética de la codorniz. In: Buxadé Carbó C (ed) Producciones cinegéticas, apícolas y otras. Zootecnia. Bases de producción animal. Tomo XII. Ediciones Mundi-Prensa, pp 109-123.

Cheng KM, Burns JT, McKinney F (1983) Forced copulation in captive mallards. III. Sperm competition. Auk 100:302-310.

Cheng KM, McIntyre RF, Hickman AR (1989) Proctodeal gland foam enhances competitive fertilization in domestic Japanese quail. Auk 106:286-291.

Clulow J, Jones RC (1982) Production, transportation, maturation, storage and survival of spermatozoa in the male Japanese Quail, Coturnix coturnix. J Reprod Fert 64:259-266.

Cohen J (1977) Reproduction. Butterworths.

Coker CR, McKinney F, Hays H, Briggs SV, Cheng KM (2002) Intromittent organ morphology and testis size in relation to mating system in waterfowl. Auk 119:403-413.

Cook PA, Harvey IF, Parker GA (1997) Predicting variation in sperm precedence. Phil Trans R Soc London [Biol] 352:771-780.

Darwin CR (1868) The variation of animals and plants under domestication. John Murray.

Dean R, Nakagawa S, Pizzari T (2011) The risk and intensity of sperm ejection in female birds. Amer Nat 178:343-54.

Derégnaucourt S (2000) Hybridization entre la caille des blés (Coturnix c. coturnix) et la caille japonaise (Coturnix c. japonica): Mise en evidence des risques de pollution génetique des populations naturelles par les cailles domestiques. PhD Dissertation, Université Rennes I.

Derégnaucourt S, Guyomarc'h JC, Belhamra M (2005a) Comparison of migratory tendency in European quail Coturnix c. coturnix, domestic Japanese quail Coturnix c. japonica and their hybrids. Ibis 147:25-36. 
Derégnaucourt S, Guyomarc'h JC, Spanò S (2005b) Behavioural evidence of hybridization (Japanese $\mathrm{x}$ European) in domestic quail released as game birds. Appl Anim Behav Sci 94:303-318.

Dickinson JL (1986) Prolonged mating in the milkweed leaf Beetle Labidomera clivicollis clivicollis (Coleoptera: Chrysomelidae): a test of the "Sperm-Loading" hypothesis. Behav Ecol Sociobiol 18:331-338.

Eberhard WG (1996) Female control: sexual selection by cryptic female choice. Princeton Univ Press.

Finseth FR, lacovelli SR, Harrison RG, Adkins-Regan EK (2013) A nonsemen copulatory fluid influences the outcome of sperm competition in Japanese quail. J Evol Biol 26:1875-89.

Fox J, Weisberg S (2011) An R Companion to Applied Regression, second ed. Sage.

Gage MJG (1994) Associations between body size, mating pattern, testis size and sperm length across butterflies. Proc R Soc Lond [Biol] 258:247-54.

Gage MJG, Morrow EH (2003) Experimental evidence for the evolution of numerous, tiny sperm via sperm competition. Curr Biol 13:754-757

Gallego S, Puigcerver M, Rodríguez-Teijeiro JD, Rodrigo-Rueda FJ, Roldán G (1993) Algunos aspectos fenológicos y de la biología de la reproducción de la codorniz (Coturnix coturnix) en Cataluña (España). Historia Animalium 2:125-136.

Guyomarc'h J-C (2003) Elements for a common Quail (Coturnix c. coturnix) management plan. Game Wildlife Science 20:1-92.

Guyomarc'h J-C, Combreau O, Puigcerver M, Fontoura P, Aebischer N (1998) Coturnix coturnix Quail. BWP Update. The Journal of Birds of the Western Palearctic 2:27-46.

Jennions, M. D. and Passmore, N. I. (1993) Sperm competition in frogs: testis size and a 'sterile male' experiment on Chiromantis xerampelina (Rhacophoridae). Biol J Linn Soc 50:211220.

Kalinowski ST, Taper ML, Marshall TC (2007) Revising how the computer program CERVUS accommodates genotyping error increases success in paternity assignment. Mol Ecol 16:1099-1106.

Kayang BB, Inoue-Murayama M, Hoshi T, Matsuo K, Takahashi H, Minezawa M, Mizutani M, Ito $S$ (2002) Microsatellite loci in Japanese quail and cross-species amplification in chicken and guinea fowl. Genet Select Evol 34:233-253. 
Perennou C (2009) European Union Management Plan 2009-2011. Common Quail, Coturnix

Kayang BB, Vignal A, Inoue-Murayama M, Miwa M, Monvoisin JL, Ito S, Minvielle F (2004) A first-generation microsatellite linkage map of the Japanese quail. Anim Genet 35:195-200.

Kempenaers B (1999) Extra-pair paternity and egg hatchability in tree swallows: evidence for the genetic compatibility hypothesis. Behav Ecol 10:304-311.

Marshall TC, Slate J, Kruuk LE, Pemberton JM (1998) Statistical confidence for likelihood-based paternity inference in natural populations. Mol Ecol 7:639-55.

Martin PA, Reimers TJ, Lodge JR, Dzuik PJ (1974) The effect of ratios and numbers of spermatozoa mixed from two males on the proportion of offspring. J Reprod Fert 39:251258.

Miranda J, Xavier P, Mahecha G, Marques Jr A (2013) Período de permanência de espermatozoides em glândulas hospedeiras de espermatozoides e glândulas infundibulares em codorna de corte. Arquivo Brasileiro de Medicina Veterinária e Zootecnia 65:19-28.

Møller AP (1988) Testes size, ejaculate quality and sperm competition in birds. Biol J Linn Soc 33:273-283.

Møller AP (1989) Ejaculate quality, testes size and sperm production in mammals. Funct Ecol 3:91-96.

Møller AP (1991) Sperm competition, sperm depletion, paternal care, and relative testis size in birds. Amer Nat 137:882-906.

Møller AP, Briskie JV (1995) Extra-pair paternity, sperm competition and the evolution of testes size in birds. Behav Ecol Sociobiol 36:357-365.

Parker GA (1970) Sperm competition and its evolutionary consequences in the insects. Biol Rev 45:525-567.

Parker GA, Simmons LW (1991) A model of constant random sperm displacement during mating: evidence from Scatophaga. Proc R Soc Lond [Biol] 246:107-115.

Parker GA, Simmons LW, Kirk H (1990) Analysing sperm competition data: simple models for predicting mechanisms. Behav Ecol Sociobiol 27:55-65.

Pearse DE, Avise JC (2001) Turtle mating systems: behavior, sperm storage, and genetic paternity. J Hered 92:206-11. Coturnix. Office for Official Publications of the European Communities. 
Pérez y Pérez F (1966) Coturnicultura. Tratado de cría y explotación industrial de codornices. Editorial Científico-Médica.

Pitnick S, Brown WD (2000) Criteria for demonstrating female sperm choice. Evolution 54:1052-1056.

Pitnick S, Wolfner M, Suarez S (2009) Ejaculate-female and sperm-female interactions. In: Birkhead TR, Hosken D, Pitnick S (eds) Sperm biology: an evolutionary perspective. Academic Press - Elsevier, pp 247-304.

Pizzari T, Parker GA (2009) Sperm competition and sperm phenotype. In: Birkhead TR, Hosken D, Pitnick S (eds) Sperm biology: an evolutionary perspective. Academic Press - Elsevier, pp 207-245.

Preston BT, Stevenson IR, Pemberton JM, Wilson K (2001) Dominant rams lose out by sperm depletion. Nature 409:681-682.

Prieto MT, Campo JL, Santiago-Moreno J (2011) Relationship among fluctuating asymmetry, morphological traits, and sperm quality in layers. Poultry Sci 90:2845-2854.

Puigcerver M (1990) Contribución al conocimiento de la biología y ecoetología de la codorniz (Coturnix c. coturnix). PhD Dissertation, University of Barcelona.

Puigcerver M, Gallego S, Rodríguez-Teijeiro JD, Rodrigo-Rueda FJ (1994) Presence of penis in the European quail Coturnix c. coturnix. Miscel·lània Zoològica 17:288-291.

Puigcerver M, Sanchez-Donoso I, Vilà C, Sardà-Palomera F, García-Galea, Rodríguez-Teijeiro JD (2014) Decreased fitness of restocked hybrid quails prevents fast admixture with wild European quails. Biol Cons 171:74-81.

Puigcerver M, Vinyoles D, Rodríguez-Teijeiro JD (2007) Does restocking with Japanese quail or hybrids affect native populations of common quail Coturnix coturnix? Biol Cons 136:628635.

R Core Team (2012). R: A language and environment for statistical computing. R Foundation for Statistical Computing. http://www.R-project.org/. Accessed 25 February 2015.

Rodrigo-Rueda FJ, Rodríguez-Teijeiro JD, Puigcerver M, Gallego S (1997) Mate switching in a non-monogamous species? The case of the common quail (Coturnix coturnix). Ethol 103:335-364.

Rodríguez-Teijeiro JD, Gallego S, Puigcerver M (1992) Análisis biométrico de la asimetria testicular bilateral en la codorniz (Coturnix c. coturnix). Historia Animalium 1:87-93. 
Rodríguez-Teijeiro JD, Puigcerver M, Gallego S, Cordero PJ, Parkin DT (2003) Pair bonding and multiple paternity in the polygamous Common quail Coturnix coturnix. Ethol 109:291302.

Rodríguez-Teijeiro JD, Sardà-Palomera F, Puigcerver M (2012) Post-breeding movements and migration patterns of western populations of common quail (Coturnix coturnix): from knowledge to hunting management. Anim Biodivers Conserv 35:333-342.

Sachs BD (1969) Photoperiodic control of reproductive behavior and physiology of the male Japanese Quail. Horm Behav 1:7-24.

Sanchez-Donoso I, Huisman J, Echegaray J, Puigcerver M, Rodríguez-Teijeiro JD, Hailer F, Vilà C (2014) Detecting slow introgression of invasive alleles in an extensively restocked game bird. FEVO 2:00015.

Sanchez-Donoso I, Vilà C, Puigcerver M, Butkauskas D, Caballero de la Calle JR, MoralesRodríguez PA, Rodríguez-Teijeiro JD (2012) Are farm-reared quails for game restocking really common quails (Coturnix coturnix)?: a genetic approach. PLoS ONE 7:e39031.

Santiago-Moreno J, Castaño C, Toledano-Díaz A, Esteso MC, López-Sebastián A, Dávila SG, Campo JL (2014) Role of sperm velocity variables associated with poultry breed in "last male precedence". Reprod Domest Anim 49:134-139.

Santos TC, Murakami AE, Oliveira CAL, Giraldelli N (2013) Sperm-egg interaction and fertility of Japanese breeder quails from 10 to 61 weeks. Poult Sci 92:205-210.

Shugart GW (1988) Utero-vaginal sperm-storage glands in sixteen species with comments on morphological differences. Auk 105:379-384

Shuster SM, Briggs WR, Dennis PA (2013) How multiple mating by females affects sexual selection. Phil Trans R Soc London [Biol] 368:20120046.

Siopes TD, Wilson WO (1975) The cloacal gland--an external indicator of testicular development in coturnix. Poult Sci 54:1225-1229.

Sittmann K, Abplanalp H (1965) Duration and recovery of fertility in Japanese quail (Coturnix coturnix japonica). Br Poult Sci 6:245-250.

Smith RL (1984) Sperm competition and the evolution of animal mating systems. Academic Press.

Stai SM, Searcy WA (2010) Passive sperm loss and patterns of sperm precedence in Muscovy ducks (Cairina moschata). Auk 127:495-502. 
611 Villanúa D, Pérez-Rodríguez L, Casas F, Alzaga V, Acevedo P, Viñuela J, Gortázar C (2008) 612 Sanitary risks of red-legged partridge releases: introduction of parasites. Eur J Wildl Res 54:199-204.

614 Warren DC, Kilpatrick L (1929) Fertilization in the domestic fowl. Poultry Sci 8:237-256. 


\section{FIGURES}

616

617 Fig. 1. Proportion of eggs fertilized by hybrid farm males (black dots) and wild males 618 (grey dots) depending on the days spent with the female (T1). Curves show the generalized 619 linear model that best fitted the data. Dashed curves show the inferred fitting of the model 620 beyond observations. Probability of egg fertilization increases over time for both male types, but 621 the probability of fertilization was higher for farm males.

622




Fig. 2. Proportion of eggs fertilized by the second male quail (marked in bold) mating with a female in different kinds of crosses. The bottom and top of each box are the first and third quartiles, the band inside the box is the median and the range of the data is marked by the whiskers. "Ø": no male before; "w": wild male; "f": farm male. The proportion of eggs fertilized by a wild (a) or a farm (b) male when the female had mated before with another male was lower than when the female had not. In the case of farm males, there were no differences regarding the origin of the first male

a

b

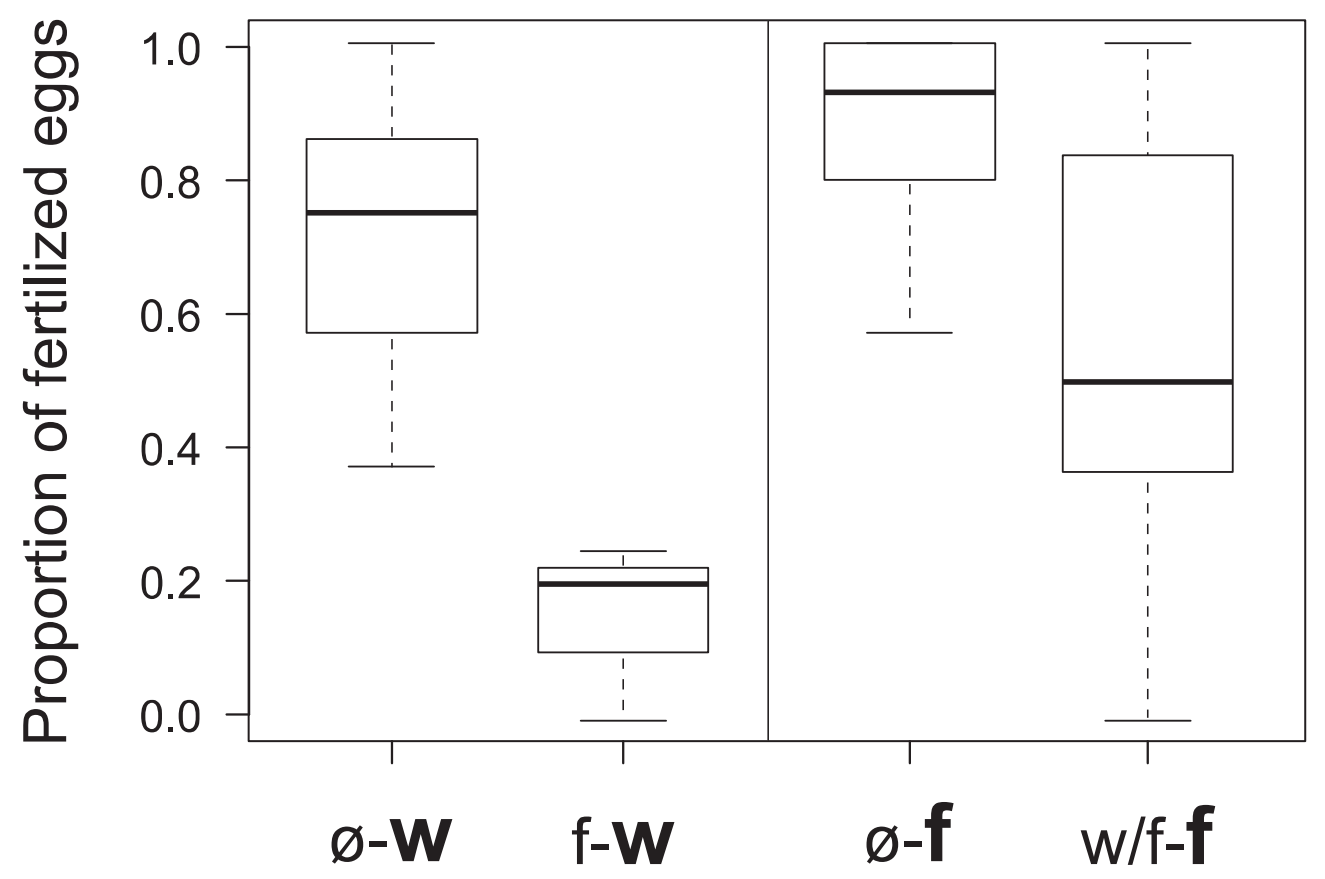


Fig. 3. Proportion of embryos sired by the second male (M2, in bold) depending on the time the first male (M1) had been with the female (T1, in days), for each male's origin combination ("w": wild male, "f": farm male). Curves show the generalized linear model that best fitted the data. Dashed curves show the inferred fitting of the model beyond observations. The longer the previous male had been with the female, the lower proportion of embryos was sired by the following male. Wild males acting as second partner sired significantly less embryos than farm males did. Although plotted separately to facilitate understanding, levels "w-f" and "f-f" were not significantly different.

642

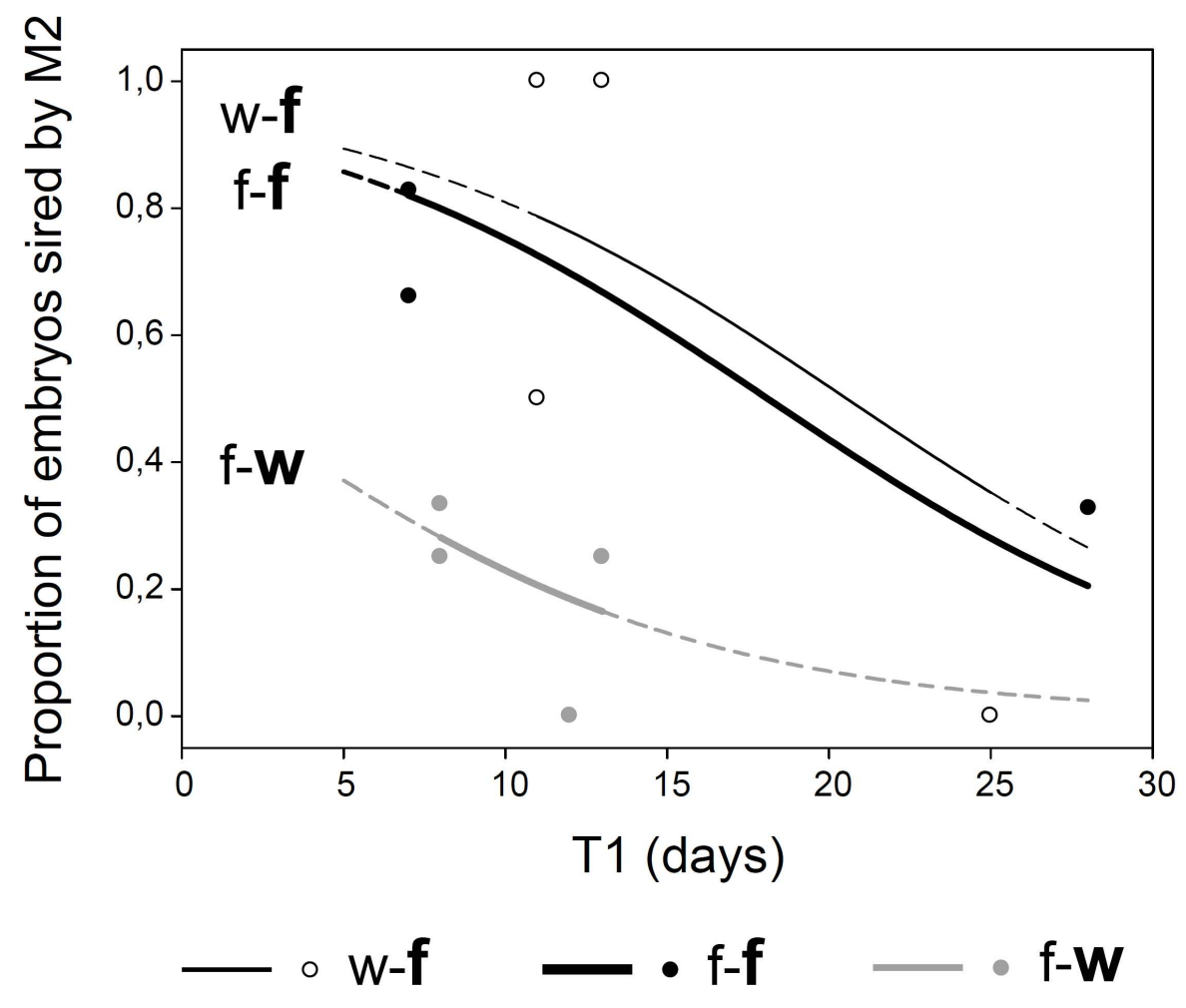

